Józef Stala

Pontifical University of John Paul II in Cracow, Poland

\title{
Der gesellschaftlich-kulturelle Kontext der aktuellen Gefährdungen für die religiöse Erziehung und Bildung in der Familie
}

\author{
Socio-cultural Context of Actual Threats \\ to Religious Upbringing and Educationin the Family
}

\begin{abstract}
In a society shaken by tensions and conflicts caused by the clash of various kinds of individualism and selfishness, children need to be enriched with a sense of the personal dignity of each individual, true love and sincere service to the others, especially the poorest and those in most need. The family is the first and fundamental school of upbringing: as a community of life and love. Every Christian family finds its mission received from God in self-giving that inspires the love of husband and wife for each other and the self-giving that is practiced in the relationships between brothers and sisters and the different generations living together in the family. The author of this article shows the actual threats to religious upbringing and education in the family with special attention given to the postmodern socio-cultural context. He also highlights financial, social, moral and religious crisis influencing the family life and education. Then asks for the roots of these negative phenomena and searches for the pedagogical solution.
\end{abstract}

\section{Keywords}

The family, education, upbringing, religion, threats.

Die Teilhabe der Familie am Heilsplan Gottes beschränkt sich nicht nur auf ihre Beteiligung am schöpferischen Wirken Gottes. Die Familie ist ebenso die vortrefflichste und natürlichste Umgebung für die Erziehung und 
die Bildung des Menschen ${ }^{1}$. Religiöse Erziehung und Bildung in der Familie finden ihre Grundlage in der Erfüllung der von Gott empfangenen Sendung, immer mehr zu einer Gemeinschaft des Lebens und der Liebe zu werden². Religiöse Erziehung und Bildung in der Familie stellen die Fortführung und die Erfüllung des schöpferischen Handelns Gottes dar. Wenn die Eltern einen neuen Menschen in Liebe und für die Liebe zur Welt bringen, nehmen sie damit auch die Aufgabe an, ihm ein in seiner Ganzheit menschliches Leben zu ermöglichen. Bei der Geburt des Menschen ist Gott selbst anwesend. Der neue Mensch, der aus der ehelichen Vereinigung zweier Personen entsteht, trägt das besondere Abbild Gottes und die Ähnlichkeit mit Ihm in die Welt hinein. Indem die Eltern dem neuen Menschen das Leben schenken, geben sie ihm auch das Abbild Gottes weiter, das sie in sich tragen. Wenn sie das eigene Kind bei sich aufnehmen, nehmen sie das Geschenk Gottes, das Abbild Gottes auf. Sie sind dazu aufgerufen, dieses Abbild Gottes, ihr Kind, der gesamten Gesellschaft vorzustellen und zu schenken. Die Familie ist die besondere Gemeinschaft von Personen, welche die Liebe Gottes hier auf Erden repräsentiert. Die wahrhafte Liebe der Eheleute drückt sich erst dadurch umfassend aus, dass die Eltern die religiöse Erziehung und Bildung in der Familie sowie ihre allgemeinen Erziehungsaufgaben aufnehmen und damit den Sendungsauftrag Gottes erfüllen ${ }^{3}$.

Durch die Weitergabe des Lebens an ihr Kind haben die Eltern Anteil am Schöpfungswerk Gottes. In den folgenden Jahren sind sie durch die Erziehung und Bildung ihrer Nachkommen an Seiner väterlichen und gleichzeitig mütterlichen Pädagogik beteiligt. Die göttliche Vaterschaft ist das wahrhafte

1 Vgl. E. Osewska, Możliwości i ograniczenia polityki rodzinnej w krajach Unii Europejskiej, in: Rodzina jako środowisko rozwoju człowieka, Hrsg. W. Piotrowski, Tarnów 2004, S. 89-119; H. Lombaerts, E. Osewska, The Modern Christian Family as a First Setting for Religious and Moral Education?, in: Religious Education/Catechesis in the Family: A European Perspective, Hrsg. E. Osewska, J. Stala, Warszawa 2010, S. 11-25; Rodzina. Bezcenny dar i zadanie, Hrsg. J. Stala, E. Osewska, Radom 2006.

2 Vgl. Familiaris consortio 17.

3 Vgl. J. Stala, Der Mensch als Person: Die bestimmende Grundlage für Johannes Paul II. in seinem Bild von der Familie, ,,The Person and the Challenges“ 2 (2012) Nr 2, S. 41-59; B. Mierzwiński, Mężczyzna - mąż - ojciec, Otwock 1996; E. Osewska, Uwarunkowania wychowania religijnego w rodzinie, in: W kręgu rodziny, Hrsg. E. Osewska, J. Stala, Poznań 2003, S. 13-21; J. Stala, E. Osewska, Sociological Aspects of Family Religious Education in Poland, in: Religious Education / Catechesis in the Family. A European Perspective, Hrsg. E. Osewska, J. Stala, Warszawa 2010, S. 167-177; J. Stala, Katecheza rodzinna. Próba teologicznego zarysu zagadnienia, in: Rodzina. Bezcenny dar i zadanie, Hrsg. J. Stala, E. Osewska, Radom 2006, S. 182-230. 
Vorbild jeglicher Elternschaft auf der gesamten Welt, insbesondere für die menschliche Mutter- und Vaterschaft. Das uralte Wort des Vaters, das zum Menschen geworden ist, offenbarte dem Menschen das ganze Ausmaß seiner Gotteskindschaft. Darin zeigte sich ihm auch die spezifische Bedeutung von Erziehung und Bildung für den Menschen. Durch Christus wird alle Erziehung, innerhalb der Familie wie außerhalb, in die heilschaffende Dimension der göttlichen Pädagogik hineingestellt, die auf die Menschen und auf die Familien ausgerichtet ist und ihren Gipfel findet im österlichen Geheimnis von Tod und Auferstehung des Herrn ${ }^{4}$.

Darum erscheint es nur zu berechtigt, in dem vorliegenden Artikel die Frage nach aktuellen Gefährdungen für die religiöse Erziehung und Bildung in der Familie aufzugreifen und dabei insbesondere den gesellschaftlichkulturellen Kontext zu erörtern. Zunächst werden Gefährdungen für das religiöse Erziehungsumfeld in der Familie aufgezeigt. Die folgenden Teile befassen sich mit der ökonomischen und gesellschaftlich-moralischen Krise, dem Pluralismus und dem Liberalismus sowie mit der Krise der Religion. Denn alle diese Faktoren beeinflussen die abschließend vorgestellten Veränderungen und Umbrüche, die sich derzeit in der Familie vollziehen.

\section{Gefährdungen für das religiöse Erziehungsumfeld in der Familie}

Die Hoffnungen, die mit der Familie als Erziehungsgemeinschaft und als Ort für eine gelungene religiöse Bildung verbunden sind, werden in einer Gesellschaft noch offensichtlicher, in der es immer schwieriger wird, überhaupt eine wirkliche Gemeinschaft zu schaffen. In den Familien unseres Zivilisationsbereichs treten derzeit jedoch bedeutend mehr Probleme auf als in traditionellen Familien, die nicht mit der Vielzahl an Bedrohungen konfrontiert sind, welche die zivilisatorische Entwicklung mit sich brachte. Diese ist unvermeidlich mit Veränderungen des gesamten Gesellschaftsstruktur verknüpft ${ }^{5}$.

In der traditionellen Familie ist der Erziehungs- und Bildungsprozess auf natürliche Art und Weise verlaufen, also durch die Beteiligung des Kindes an allen Dimensionen ihres Lebens: an der Arbeit, an den Festen und am

4 Vgl. Brief an die Familien: Gratissimam sane 16.

5 Vgl. Hermeneutics and Religious Education, Hrsg. H. Lombaerts, D. Pollefeyt, LeuvenParis-Dudley 2004. 
Brauchtum $^{6}$. Die Lebensbedingungen der modernen Familie machen eine derartig natürliche Erziehung dagegen nahezu unmöglich ${ }^{7}$. Somit entsteht eine Leere, die nicht immer mit bewusstem und geplantem erzieherischen Einwirken gefüllt werden kann, da insbesondere die katholische Familie in dieser Hinsicht weitere Anforderungen erfüllen sollte, denn in einer solchen Familie ist das Kind gleichzeitig auch ein Kind Gottes, ein Christ.

Man kann versuchen, unterschiedliche Ursachen für die derzeitige Sachlage aufzuzeigen. Dabei lässt sich nur schwerlich übersehen, dass die Massenmedien heute einen der grundlegenden Erziehungs- und Bildungsfaktoren ausmachen, die häufig ein anti-familiäres Klima schaffen, indem sie das Zusammenleben in der Ehe oder der Familie herabwürdigen ${ }^{8}$. Die Familie befindet sich im Zentrum eines Machtkampfes zwischen zwei sich widersprechenden Lebensformen. Die eine, die als Zivilisation des Lebens und der Liebe bezeichnet wird, beginnt in Gott, der die Liebe ist, und verkündet die Liebe Gottes und des Menschen. Die zweite Lebensform richtet sich als Zivilisation des Todes und der Tötung gegen die eigentliche Zivilisation. Ihre Quelle sind der Atheismus, die Abwendung von Gott, die Zurückweisung sittlicher Normen im Namen einer falsch verstandenen Freiheit ${ }^{9}$. Sie spricht für die Legalisierung homosexueller Verbindungen, propagiert einen sexuell freizügigen Lebensstil, befürwortet die Abtreibung

6 J. Mastalski bemerkt:,Es scheint, das einer derwichtigsten für die Familie toxischen Faktoren in der abnehmenden Menge und Qualität der gemeinsam verbrachten Zeit besteht. Der Kontakt mit den Eltern ist für das Kind einer der bedeutendsten, wenn nicht der bedeutendste Faktor überhaupt, um seine Entwicklung zu stimulieren”. J. Mastalski, Szkolne interakcje zaburzajace skuteczne wychowanie, Kraków 2005, S. 94.

7 Vgl. J. Stala, Familienkatechese in Polen um die Jahrhundertwende. Probleme und Herausforderungen, Tarnów 20081 Dzisiejsze aspiracje katechezy rodzinnej. Problemy i wyzwania, Hrsg. J. Stala, Kielce 2005.

8 Vgl. H. Lombaerts, The Impact of the Status of Religion in Contemporary Society upon Interreligious Learning, in: Interreligious Learning, Hrsg. D. Pollefeyet, Leuven 2007, S. 8186; Hermeneutics and Religious Education, Hrsg. H. Lombaerts, D. Pollefeyet, Leuven 2004; H. Lombaerts, Komunikacja wiary dzisiaj, in: Komunikacja wiary w Trzecim Tysiacleciu, Hrsg. S. Dziekoński, Olecko 2000, S. 25-39; H. Lombaerts, ICT jako główne wsparcie globalnego świata i globalnego środowiska edukacyjnego, in: Hrsg. A. Bałoniak, J. Szpet, Między tradycja a wspótczesnościa, Poznań 2008, S. 73-90; E. Osewska, To Educate in a Diversified Europe, „The Person and the Challenges“" 1 (2011) Nr 1, S. 72-73; E. Osewska, Le pèlegrinage à Czestochowa. Lieu d'éducation dans la foi, «Lumen Vitae Revue » (2007), S. 247-265; E. Prijatelj, Geistige Dynamik von Vorschulkindern und deren Einführung in den Glauben, „Christlich pädagogische Blätter“ (2007) Nr. 2, S. 100-104; E. Prijatelj, Psihološka dinamika rasti v veri, Ljubljana 2008.

9 Vgl. Brief an die Familien: Gratissimam sane 6-17. 
ohne jegliche Einschränkung und erkennt empfängnisverhütende Mittel als einziges Modell für die Familienplanung $a^{10}$.

Die christliche Familie sieht sich häufig dem Druck zweier gegensätzlicher Kräfte ausgesetzt. Die eine reißt die Familie gewissermaßen aus dem Haus heraus: Die Familie veräußert sich komplett, stellt sich nur auf die anderen ein. Alle Interessen und Angelegenheiten konzentrieren sich dann nach außen. Folglich verbleibt das familiäre Heim - sowohl für die Eltern (mehrfach arbeiten beide nicht zuhause) als auch für die Kinder - der einzige Ort, wo man irgendeine Mahlzeit (morgens oder abends) einnimmt, sich über Ausgaben und alltägliche Ereignisse austauscht und übernachtet. Die zweite, der eben beschriebenen entgegengesetzte Kraft bewegt einige Familien besonders in der Situation der modernen Welt und der aktuellen Lebensbedingungen für die Menschen dazu, sich in den vier Wänden des eigenen Heims einzuschließen. Bei einer großen Anzahl von Familien, insbesondere bei den empfindlichen und sensiblen, wird die Wohnung nur für die Arbeit verlassen, für den Weg zur Arbeit, um Einkäufe zu erledigen, um zu lernen, zu studieren oder den Beruf auszuüben. Alle anderen Dinge, alle Freuden und Erlebnisse, alle lebensnotwendigen Beschäftigungen finden ausschließlich im familiären Heim statt. Beide extremen Ausprägungen von Familie erfüllen nicht die Anforderungen, um als Vorbild einer christlichen Familie zu gelten.

Die Gesellschaft Polens befindet sich etwa seit 1990 in einer Phase tiefgreifender Umbrüche. Nach außen ist die Kirche frei von Druck und Einschränkungen. Es kommt jedoch Abneigung gegen eine Kirche auf, die als Institution allzu unabhängig und autonom betrachtet wird. Man wirft der Kirche vor, zu konservativ und nicht bereit zu sein, dem modernen Menschen dabei zu helfen, eine neue demokratische Welt zu gestalten ${ }^{11}$. Die Kirche, die einige Jahrzehnte vorher noch als Fundament der kulturellen Werte und als

${ }^{10} \mathrm{Vgl}$. A. Gellel, Adaptive Religious Education at the Service of Inventiveness: A scientific way of being creative and effective in Religious Education, „The Person and the Challenges“ 1 (2011) $\mathrm{Nr}$ 1, S. 99-111.

${ }^{11}$ Vgl. E. Osewska, L'educazione oggi in un'Europa diversificata, in: Europa, scuola, religioni. Monoteismi e confessioni cristiane per una nuova cittadinanza europea, Hrsg. F. Pajer, Torino 2005, S. 47-64; H. Lombaerts, E. Osewska, Historical and Geo-Political Reality of a United Europe, in: S. Gatt, H. Lombaerts, E. Osewska, A. Scerri, Catholic Education, European and Maltese Perspectives. Church School's response to future challenges, Floriana 2004, S. 27-43; H. Lombaerts, Edukacja z perspektywy europejskiej, „Horyzonty Wychowania“ (2002) Nr 2, S. 165-179; Współdziałanie Kościoła i państwa na rzecz malżeństwa i rodziny, Hrsg. J. Krukowski, T. Śliwowski, Łomża 2005; Oblicze wspótczesnej rodziny polskiej, Hrsg. B. Mierzwiński, E. Dybowska, Kraków 2003; J. Mariański, Czy zakrystia wystarczy do działalności Kościoła?, in: Problemy wspótczesnego Kościoła, Hrsg. M. Rusecki, Lublin 
Garant für die gesellschaftliche Ordnung angesehen wurde, wird heute immer häufiger als Bedrohung für Demokratie und Freiheit wahrgenommen. In den neunziger Jahren des zwanzigsten Jahrhunderts wurde es sogar zur Mode, die gesellschaftlichen und politischen Einflussmöglichkeiten der Kirche aufzubauschen, irgendwelche Offensiven der Kirche und der mit ihrverbundenen Personen insbesondere im Bereich legislativer Angelegenheiten zu betonen, aber auch die Gefahr eines katholischen Fundamentalismus wahrzunehmen, der sich u. a. in einer Rückkehr des katholischen Religionsunterrichts an die staatlichen Schulen ausdrücken sollte. Derzeit bemühen sich laizistische Strömungen ebenso darum, die Katholische Kirche als eine Art Folkloreverband darzustellen, der jedoch von Tag zu Tag an Wert verliert. Folglich wird der Kirche häufig vorgeschlagen, sich auf die rein religiösen oder auch karitativen Dienste zu konzentrieren, besonders die postkommunistischen Eliten unterstützen eine grundsätzliche Trennung von Kirche und Staat und verbreiten die Ideologie von einem weltanschaulich neutralen Staat.

Kritik an der Kirche findet für gewöhnlich Auftrieb in Verbindung mit der Diskussion um weitere Gesetzesprojekte zum Schutz des ungeborenen Lebens und zum Religionsunterricht an den Schulen. Daher wird vor allem in den gesellschaftlichen Medien ein Stereotyp von Kirche als Institution propagiert, die allem Anschein nach die gesamte Gesellschaft beherrschen will ${ }^{12}$. Obwohl allmählich der Personenkreis derer wächst, welche entschieden und bewusst die Sittenlehre der Kirche annehmen, gibt es weiterhin diejenigen, deren Einstellung wesentliche Elemente der christlichen Doktrin in Frage stellt und deren Standpunkt sich so beschreiben lässt: „Ich bin Katholik, aber... "13. Insbesondere die Ehe- und Familienmoral, welche nach der kirchlichen Lehre im Leben des Katholiken durch die religiösen Werte inspiriert sein soll, ist bei vielen für gewöhnlich eher selektiv ${ }^{14}$.

1997, S. 44; B. Kl’uska, Idea chrześcijańskiego nawrócenia w procesie resocjalizacji, w: Socjalizacjawyzwanie wspótczesności, Hrsg. J. Stala, Tarnów 2010, S. 75-87.

${ }^{12}$ Vgl. J. Kondziela, Strukturreformen und Einstellungen in Polen, in: Vom Sozialismus zum demokratischen Rechtsstaat. Der Beitrag der katholischen Soziallehrezu den Transformationsprozessen in Polen und in der ehemaligen DDR, Hrsg. M. Spieker, Paderborn 1992, S. 97.

${ }^{13}$ Vgl. J. Mariański, Johannes Paul II. als moralische Autorität in der polnischen Gesellschaft, "The Person and the Challenges" 2 (2012) Nr 1, S. 21-50; J. Mariański, Kościót katolicki w spoteczeństwie obywatelskim, Lublin 1998, S. 121.

${ }_{14}$ Vgl. J. Stala, Die Transzendenz als bestimmendes Merkmal der Person in der Anthropologie und der Pädagogik Johannes Pauls II., „The Person and the Challenges“ 2 (2012) Nr 1, S. 61- 


\section{Die ökonomische und gesellschaftlich-moralische Krise}

Von besonderer Bedeutung für die Ausgestaltung der polnischen Familie im Hinblick auf die Moral hat die in den Zeiten des Kommunismus aufgekommene und bis heute andauernde ökonomische und gesellschaftlich-sittliche Krise der Gesellschaft. Seit den 90er Jahren geht die Kirche mit diesem Thema offensiv $u^{15}$. Die materielle Lage de Familie stellt ein Problem dar, das man nicht unterschätzen darf, wenn man über die Familie spricht. Nicht wenige Aspekte der gesellschaftlich-ökonomischen Situation der Familie, wie etwa die Lebensund Wohnbedingungen oder die Berufstätigkeit verheirateter Frauen, erfordern eine sofortige Analyse, wenn man das Tempo berücksichtigt, in welchem diese Umbrüche in einem Land vor sich gehen, in dem sich die allgemeinen Lebensbedingungen als Folge der ökonomischen Situation rapide verändern.

Geradezu ein Massenphänomen ist die sogenannte verdeckte Arbeitslosigkeit einer großen Anzahl von Menschen, die in Dörfern leben und in kleinen, häufig unrentablen Landwirtschaftsbetrieben arbeiten. Beunruhigend ist auch die Tatsache, dass in einem gewissen Umfang Ehestand und Mutterschaft für viele Frauen die Grundlage dafür sind, vor den erschwerten Bedingungen zu resignieren. Lediglich etwa jede fünfte verheiratete Frau nimmt nach der Geburt des Kindes ihre Berufstätigkeit nicht wieder auf. Für eine bedeutende Anzahl von Familien ist die Erwerbstätigkeit der Frau sogar eine ökonomische Notwendigkeit, aber ein von der Mutter im Durchschnitt neun Stunden am Tag verlassenes Heim trägt erheblich zur Destabilisierung des Familienlebens bei ${ }^{16}$.

\section{Pluralismus und Liberalismus}

Eines der wesentlichsten Merkmale unserer heutigen Zeit besteht im Pluralismus. Die intensive Industrialisierung und die Urbanisierung haben

75; A. Drożdż, Permisywizm moralny, Kielce 2005; A. Drożdż, Konsumizm. Ocena moralna na podstawie encyklik Jana Pawła II, Tarnów 1997.

${ }^{15}$ Vgl. B. Drożdż, Postuga społeczna Kościoła. Studium pastoralne w świetle nauczania wspótczesnego Kościoła, Legnica 2009; W. Przygoda, Posługa charytatywna Kościoła w Polsce. Studium teologiczno-pastoralne, Lublin 2004; J. Zając, Troska Kościoła o chorych, Płock 2005; W. Szymański, Towarzystwo dobroczynności wobec kwestii społecznych, Płock 2005; Kościót w Polsce wobec potrzebujacych, Hrsg. M. Chmielewski, Lublin 1994.

${ }^{16}$ Vgl. B. Mierzwiński, Kościót wobec problemu bezrobocia, Ząbki 2004; A. Solak, Wychowanie chrześcijańskie i praca ludzka. Studium wspótzależności, Warszawa 2004. 
erheblich zu seiner Verbreitung und Beschleunigung beigetragen. Dieser Prozess verstärkteauchdas AuftretengewisserSäkularisierungserscheinungen, womit die allmählich voranschreitende Befreiung der gesellschaftlichen Sektoren von der Beherrschung durch religiöse Institutionen und geltende Systeme gemeint ist. Diese aufkommende Säkularisierung steht im direkten Gegensatz zu der früheren Sakralisierung und zur Monopolstellung der traditionellen Gesellschaft.

Alle diese Erscheinungen müssen zweifellos, ohne eine extreme Katastrophenstimmung herauf zu beschwören, zum Gegenstand von Analysen derer werden, die sich mit der Familie beschäftigen. Ohne eine Diagnose der vorliegenden Faktoren lässt sich nur schwerlich darüber diskutieren, wie die Familie aktuell eine wie auch immer geartete sittliche, oder sogar eine bewusst durchgeführte religiöse Erziehung und Bildung realisieren kann.

Die Verbreitung eines permissiven Moralverständnisses ${ }^{17}$, auch wenn damit scheinbar die Freiheit geachtet sowie die Fähigkeit zu Entscheidungen anerkannt werden, über die jeder Mensch verfügt, führt in der Realität $\mathrm{zu}$ einer Erosion der traditionellen Werte, die sich auf Ehe und Familie beziehen. Der Einfluss der Kirche auf das Leben der Ehepartner und der Familien schwindet zusehends. Man kann sogar sagen, dass dadurch eine tiefe Moralkrise der Kirche, die diese von innen aushöhlt, ebenso offenbar wird wie eine Dissonanz zwischen der traditionellen kirchlichen Lehre und der modernen, oder auch postmodernen Mentalität. Ein beachtlicher Teil der Katholiken formuliert weiter gehende Postulate, einige Punkte der kirchlichen Sittenlehre zu liberalisieren. Es werden Forderungen hörbar, die Entscheidungsfreiheit zu erweitern, und darüber nachzudenken, was in dieser Doktrin beibehalten und was geändert werden muss. Das Entstehen einer pluralistischen Gesellschaft, in der weltanschauliche Toleranz und die Freiheit zu umfangreichen Wahlmöglichkeiten vorherrschen, wo aber auch unterschiedliche soziale Gruppen mit verschiedenartigen Wertevorstellungen, Normen und Verhaltensmustern miteinander konkurrieren und damit die Sphären des „sacrum i profanom” ausdrücklich voneinander abtrennen, begünstigt die Umgestaltung der Funktionen, welche die Familie zu erfüllen hat. Einige tendieren sogar dazu, von einer normativen Revolution in den polnischen Familien zu sprechen, andere fordern eine Revision der kirchlichen Sexuallehre. Der aufkommende ethische Individualismus

\footnotetext{
${ }_{17}$ Vgl. A. Drożdż, Permisywizm moralny, Kielce 2005.
} 
erhöht die Ablehnung der von oben verordneten ideologischen Belehrungen, insbesondere dann, wenn sie verwaltungsmäßig aufgezwungen werden ${ }^{18}$. Eines der wesentlichsten Kennzeichen der modernen Gesellschaftsstruktur stellt die Differenzierung dar. Die Religion ist nicht nur dazu verpflichtet, die aktuellen Grundsätze einer strukturellen Differenzierung der weltlichen Sphäre zu akzeptieren, sondern muss sich der gleichen Dynamik unterwerfen und ihre eigene, autonom unterscheidbare Sphäre entfalten.

\section{Die Krise der Religion}

Wenn die Religion auch mit dem ansteigenden Niveau der gesellschaftlichen Modernisierung in vielen sozialen Bereichen zurückgeht, so bleibt sie im privaten Bereich durchaus aufrecht erhalten. Der öffentliche Raum wird dagegen im Hinblick auf die Religion allmählich zu einer neutralen Zone. Die gleiche Religion wird unvermeidbar zu einer rein privaten Angelegenheit ${ }^{19}$, ist gleichzeitig aber nicht mehr so selbstverständlich wie früher ${ }^{20}$. Manche tendieren sogar schon dazu, die traditionelle Kirche für tot zu erklären ${ }^{21}$.

${ }^{18}$ Vgl. J. Orzeszyna, Teologiczno-moralny aspekt niepłodności w matżeństwie, Kraków 2005; J. Mariański, Rodzina wobec wartości: rozpad czy transformacja?, in: Rodzina: źródto życia i szkoła miłości, Hrsg. D. Kornas-Biela, Lublin 2000, S. 99.

${ }^{19}$ Vgl. J. Mariański, Kryzys moralny czy transformacja wartości? Studium socjologiczne, Lublin 2001, S. 47-49; B. R. Wilson, Religia w zsekularyzowanym społeczeństwie, in: Socjologia religii. Antologia tekstów, Hrsg. W. Piwowarski, Kraków 1998, S. 357.

${ }^{20}$ „Die religiösen Werte sind Behauptungen, die aus der übernatürlichen Welt über die Thematik dessen emanieren, was gut oder schlecht ist, was richtig und was falsch ist. Obwohl in der Gesellschaft auch andere Werte existieren, sind diese von besonderer Bedeutung, weil sie im Zusammenhang mit heiligen Wesen und Mächten einer übernatürlichen Wirklichkeit stehen“. J.H. Turner, Socjologia. Podstawowe pojęcia i ich zastosowanie, Poznań 1998, S. 156.

${ }^{21}$ Auf der Grundlage von soziologischen Erhebungen lassen sich in Polen drei Grundhaltungen bezüglich der Religion unterscheiden. Die erste Gruppe bilden die Nichtgläubigen (ungefähr 17 Prozent), von denen sich nur ein Teil (7 Prozent) als Atheisten bezeichnet, die ihren Unglauben theoretisch zu begründen versuchen. Folglich steht die Mehrzahl dieser Gruppe (10 Prozent) der Religion indifferent gegenüber, sie kennzeichnen sich durch einen praktischen Materialismus. Zur zweiten Gruppe zählen Menschen mit einer selektiven, auswählenden Einstellung zur Religion (etwa 30 Prozent). Sie gehören der Kirche theoretisch in irgendeiner Form an, lehnen jedoch bestimmte dogmatische Wahrheiten und sittliche Normen ab, welche die Kirche verkündet. Die dritte und zahlenmäßig stärkste Gruppe (annähernd 50 Prozent) machen die gläubigen oder tief gläubigen Menschen aus. Vgl. J. Mariański, Kryzys moralny czy transformacja wartości? Studium socjologiczne, Lublin 2001, S. 50. 
Einige Soziologen betrachten die Krise der Religion in der modernen Welt der Gegenwart vor allem als Krise der Glaubensvermittlung, hervorgerufen durch den Bruch mit der überlieferten Tradition ${ }^{22}$. Soziologische Untersuchungen zeigen einen systematischen Rückgang der religiösen Praxis auf, eine steigende Anzahl formeller Kirchenaustritte und eine wachsende psychosoziale Distanz zur Kirche als Institution.

Die Krise der Religion ist heute vor allem eine Krise im Hinblick auf die Übertragung von religiös-kirchlichen Werten und Normen. Falls es nicht zu einem endgültigen Zerreißen der Bindung an die Religion kommt, dann verbleibt diese lediglich eine von vielen separaten Sektoren der Wirklichkeit und verliert ihre Rolle bei der Integration des gesellschaftlichen Lebens. Es scheint sogar so, dass die gesamte säkularisierte europäische Kultur vom Christentum nichts mehr erwartet, dass viele Menschen heute so leben, als existiere Gott nicht ${ }^{23}$. Denn Gott ist bereits von ihrem existenziellen Horizont verschwunden. Für den vom praktischen Materialismus durchdrungenen Menschen ist Gott durchaus entbehrlich. In seinem alltäglichen Leben hat er für Ihn weder Zeit noch Platz. In dieser säkularisierten Welt nahm Johannes Paul II. jedoch auch Zeichen der Hoffnung wahr. Denn er bemerkte, dass in den am meisten säkularisierten Gesellschaften eine neue Generation gläubiger Menschen heranwächst, die sich nach ethischen Grundsätzen und dauerhaften religiösen Werten sehnt, und neue Ausdrucksformen für ihren Glauben sucht ${ }^{24}$.

Die Prozesse, die sich heute vollziehen, lassen sich folglich nicht eindeutig einschätzen. Denn zwischen den beiden Strömungen - dem Schwund der Religion und der Rückkehr des sacrum - erstreckt sich ein breites Spektrum unterschiedlichster Haltungen gegenüber Religion und Kirche, bis hin zu einer individualisierten Formen des religiösen Lebens, die sich an den eigenen Bedürfnisse und Interessenslagen orientieren ${ }^{25}$. Der postmoderne

${ }^{22}$ Vgl. Jungsein in Deutschland. Jugendliche und junge Erwachsene 1991 und 1996. Hrsg. von R. K. Silbereisen, L. A. Vaskovic, J. Zinnecker, Opladen 1996, S. 113-126; B. Schäfers, Soziologie des Jugendalters. Eine Einführung, Opladen 1994, S. 157-163.

${ }^{23}$ Vgl. Jan Paweł II, Przemówienie z 19 VI 1998 r. podczas mszy św. w katedrze w Salzburgu, „L'Osservatore Romano” 19 (1998) Nr 10, S. 24.

${ }^{24}$ Vgl. Jan Paweł II, Przemówienie do uczestników plenarnego zebrania Sekretariatu dla Niewierzacych 5 III 1988 r., ,L'Osservatore Romano“ 9 (1988) Nr 3-4, S. 28.

${ }^{25} \mathrm{Vgl}$. P. L. Berger, Wenn die Welt wankt. Pluralismus ist eine Chance für Christen, „Lutherische Monatshefte“ 32 (1993) Nr. 12, S. 12-16. 
Mensch ist also nicht jeglicher religiöser Motivation beraubt. Häufig ist er allerdings kein Katholik, selbst kein Christ mehr, aber in ihm ist ein neues Interesse an der „Religion” erwacht. Der Trend hin zur Religiosität ist heute nicht ganz erloschen, seine Hauptströmung verläuft jedoch eher wie neben dem Christentum ${ }^{26}$. Das zwanzigste Jahrhundert kannte zwei „Religionen”, die den einen Gott bekämpften - den Faschismus und den Stalinismus und in der Konsequenz viele Verbrechen nach sich zogen. Die Anhänger des erstgenannten „Glaubens” waren sogar bereit, ihr eigenes Leben für das „Wohl” der Rasse und des Staates zu opfern. Die Schaffung eines eigenen Norm- und Wertesystems musste dazu führen, Gott zurück zu weisen oder sogar zu hassen. Die zweite „Religion” hatte ihre eigene Dogmatik, wie etwa den Klassenkampf, die Überlegenheit des Kollektivs gegenüber dem Individuum und die Diktatur des Proletariats. In ihr vollzog sich die „Vergötterung” der Partei und des humanistischen Staats, die zur Quelle und zum Wächter des menschlichen Gewissens wurden. Das Primat von Partei und Staat verknüpfte sich mit der Zurückweisung Gottes und einer atheistischen Gesellschaft. Beide „Religionsformen” trugen zu einer Krise des Menschen und der Familie bei.

\section{Veränderungen in der Familie}

Wenn man die überaus gewichtige Rolle betrachtet, welche die Familie auch noch in unseren Zeiten zu erfüllen hat, kann man die Menge an Veränderungen nicht außer Acht lassen, die sich in ihr beständig vollziehen. Obwohl die Familie weiterhin ihre Funktion bezüglich der religiösen Erziehung und Bildung vollbringt, dann jedoch nicht mehr auf die Art und Weise wie im traditionellen Gesellschaftssystem ${ }^{27}$. Die religiöse Dimension der Familie in einer pluralistischen Gesellschaft ist aber keine allgemeine Erscheinung. Manche Familien füllen sie gänzlich aus, andere teilweise und wieder andere

${ }^{26}$ Vgl. J. Mariański, Kryzys moralny czy transformacja wartości? Studium socjologiczne, Lublin 2001, S. 58.

${ }^{27} \mathrm{Vgl}$. Wychowanie chrześcijańskie. Między tradycja a współczesnościa, Hrsg. A. Rynio, Lublin 2007; Dzisiejsze aspiracje katechezy rodzinnej. Problemy i wyzwania, Hrsg. J. Stala, Kielce 2005; Wychowanie chrześcijańskie, Hrsg. A. Solak, Warszawa 2004; E. Osewska, J. Stala, $W$ kierunku katechezy rodzinnej, Kielce 2003; Drogi katechezy rodzinnej, Hrsg. E. Osewska, J. Stala, Poznań 2002. 
überhaupt nicht. Man nimmt an, dass 80 bis 90 Prozent der Kinder auf ähnliche Weise wie ihre Eltern praktizieren, das heißt sie führen religiöse Praktiken durch. Eine ähnlich hohe Anzahl jugendlicher Menschen beteiligt sich an den religiösen Praktiken nicht so wie ihre Eltern. Wenn eine Familie als fromm bezeichnet wird, zeigen die Kinder häufiger Grundhaltungen auf, die Traditionen fortbestehen zu lassen. In weniger frommen Familien dagegen neigen sie eher zu einer Veränderung der Traditionen ${ }^{28}$. Ein nicht zu unterschätzender Aspekt ist die Tatsache, dass gerade die Männer für einen Fortbestand der religiösen Traditionen in der Familie stehen, obwohl die Religiosität unter den Frauen intensiver ausgeprägt ist.

Religiosität wie auch das Fehlen der Religiosität sind in einem bestimmten Ausmaß eine vererbbare Erscheinung. Jeglicher Mangel in diesem Bereich, insbesondere wenn ein Egoismus die Basis für eine Familiengemeinschaft bildet, der die Liebe zerstört, ist heute weitaus gefährlicher als noch vor Zeiten $^{29}$. Viele Familien kennzeichnet derzeit ein relativer materieller Wohlstand, kulturelles Engagement, die Abgeschlossenheit in sich selbst, Bindungen auf der Basis persönlicher Beziehungen, eine geringe Kinderzahl und die Gleichberechtigung der Familienmitglieder im demokratischen Sinn. Der Familienverband, der früher einen großen Kreis von Verwandten umfasste, verkleinert sich gegenwärtig immer häufiger auf lediglich zwei Elemente: die Eltern und die Kinder. Das althergebrachte Modell, in dem der Vater als Oberhaupt und Ernährer der Familie fungierte und die Mutter daheim blieb, wird von einem neuen Modell abgelöst, das sich auf das gemeinschaftliche Handeln stützt. Man kann noch nicht davon sprechen, dass die Geschlechterrollen der Eltern völlig aufgegeben sind, wohl aber davon, dass Mann und Frau gemeinsam die Verantwortung für das Kind übernehmen. Das Kind wird nicht mehr so sehr als Kontinuität der Eltern

${ }^{28} \mathrm{Vgl}$. Postawy spoleczno-religijne diecezjan tarnowskich, Hrsg. W. Zdaniewicz, T. Zembrzuski, Warszawa 2001; Kościót i religijność Polaków 1945-1999, Hrsg. W. Zdaniewicz, T. Zembrzuski, Warszawa 2000.

${ }^{29}$ Die traditionelle Familie hat die geistige Bastion des Polentums geschaffen. Das öffentliche Leben draußen trug das Brandmal der Feinde und war von Zweideutigkeit vergiftet. Die Privatheit ersetzte das gesellschaftlich-politische Leben (,öffentliche Privatheit“). In der Familie äußerte man seine politische Ansicht und schuf das Bild vom Patriotismus. „Aktionen“, die sich den Feinden widersetzten, hatten in den meisten Fällen den „Segen“ der Familie: Die Mutter schickte ihren Sohn 1944 ebenso in den Kampf wie 1863; Sie tolerierte das auf dem Dachboden versteckte Gewehr im 19. Jahrhundert wie sie ein Sofa voller Untergrundpublikationen in den Zeiten von „Solidarnośćc tolerierte. Vor allem war die Familie jedoch für die Bewahrung und die Weitergabe der Werte zuständig. 
betrachtet sondern als eigenständige Person, die über eigene Subjektivität und Rechte verfügt ${ }^{30}$. Daher wird es zu einer wichtigen Aufgabe für die Eltern, die Selbstständigkeit zu stimulieren. Das veränderte Wirtschaftssystem führte in einem weiten Bereich zu einem Rückgang des vor allem im ländlichen Raum charakteristischen patriarchalen Familientyps. Dagegen verbreitet sich das egalitäre Familienmodell, bei dem alle Familienmitglieder als Partner agieren. Diese Partnerschaftlichkeit scheint allerdings nicht nur eine Bedrohung der Familie zu sein, vielmehr öffnen sich dadurch neuartige, bisher unbekannte Dimensionen. Eine auf Liebe, Achtung und Partnerschaft basierende Erziehung und Bildung kann durchaus erfolgreicher verlaufen ${ }^{31}$, die Regeln und Gebote für das Familienleben können so besser zu Regeln und Geboten werden, die von ihren Mitgliedern internalisiert werden.

$$
* * *
$$

Im Hinblick auf die schwierige Situation von Eheleuten und Familien in Polen nach dem Jahr 1989 bemühte sich die Kirche, die Familie in den Rahmenbedingungen eines demokratischen Staates mit größerer Sorge und Aufmerksamkeit zu umgeben. Dies erfolgte unter anderem durch die Zusammenarbeit mit den dafür verantwortlichen staatlichen oder gesellschaftlichen Institutionen, auch auf dem Gebiet der Herausforderungen, welche Ehe und Familie sowie die Erziehung und die Bildung der jungen Generation betreffen ${ }^{32}$. Die Kirche war ebenfalls bestrebt, die Würde des Menschen zu verkünden, die durch das liberale Abtreibungsrecht und eine weit verbreitete Verhütungsmentalität bedroht ist. In ihrer Lehre erinnerte sie an die Notwendigkeit, die Einheit von Ehe und Familie zu wahren, deren Erhalt durch die Geringschätzung des Ehesakraments gefährdet ist. Einen

${ }^{30}$ Vgl. D. Opozda, Integracja rodziny a wiedza o matzeństwie u młodzieży, Lublin 2001.

${ }^{31} \mathrm{Vgl}$. Wychowanie chrześcijańskie. Między tradycja a współczesnościa, Hrsg. A. Rynio, Lublin 2007; A. Rynio, Integralne w myśli Jana Pawła II, Lublin 2004; J. Mastalski, Szkolne interakcje zaburzajace skuteczne wychowanie, Kraków 2005.

${ }^{32}$ Vgl. A. Skreczko, Troska Kościoła katolickiego w Polsce o matżeństwo i rodzinę w okresie Wielkiej Nowenny Tysiaclecia (1957-1966). Studium teologiczno-pastoralne, Białystok 2002; A. Skreczko, Rola Kościoła katolickiego w kształtowaniu kultury pedagogicznej rodziców w Polsce, Białystok 2011; Wspóldziałanie Kościoła i państwa na rzecz malżeństwa i rodziny, Hrsg. J. Krukowski, T. Śliwowski, Łomża 2005; Rodzina jako środowisko rozwoju człowieka, Hrsg. W. Piotrowski, Tarnów 2004; Oblicze współczesnej rodziny polskiej, Hrsg. B. Mierzwiński, E. Dybowska, Kraków 2003. 


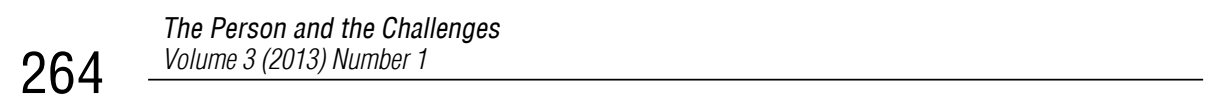

weiteren Gegenstand für die Sorge der Kirche stellten die existenziellen materiellen Lebensbedingungen der ärmeren Familien in Polen dar.

Die gewaltigen Veränderungen im aktuellen Moralverständnis und die viele Christen betreffende sittliche Permissivität erfordern wirkungsvollere Strategien und Maßnahmen im Rahmen der Erziehung und Bildung hin zu einem ganzheitlichen Menschen - zu einem Christen. Es bleibt eine große Herausforderung, die Entstehung von Familien zu fördern, die auf gesunden moralischen und religiösen Grundsätzen basieren, aber gleichzeitig auch aktiv am Leben der Gesellschaft oder der Pfarrgemeinde teilnehmen. Falls dieses Thema jedoch nicht aufgenommen wird, wird man nur schwerlich über religiöse Erziehung und Bildung in der Familie sprechen können, da sie ohne die gesunde Familie lediglich ein leerer Begriff, ein womöglich nicht realisierbares Ideal verbleibt.

\section{Bibliography}

Drogi katechezy rodzinnej, Hrsg. E. Osewska, J. Stala, Poznań 2002.

Drożdż A., Konsumizm. Ocena moralna na podstawie encyklik Jana Pawła II, Tarnów 1997.

Drożdż A., Permisywizm moralny, Kielce 2005.

Drożdż B., Postuga spoleczna Kościoła. Studium pastoralne w świetle nauczania wspótczesnego Kościoła, Legnica 2009.

Dzisiejsze aspiracje katechezy rodzinnej. Problemy $i$ wyzwania, Hrsg. J. Stala, Kielce 2005.

Gellel A., Adaptive Religious Education at the Service of Inventiveness: A scientific way of being creative and effective in Religious Education, "The Person and the Challenges" 1 (2011) Nr 1, S. 99-111.

Hermeneutics and Religious Education, Hrsg. H. Lombaerts, D. Pollefeyt, Leuven-ParisDudley 2004.

Kl'uska B., Idea chrześcijańskiego nawrócenia $w$ procesie resocjalizacji, in: Socjalizacja - wyzwanie wspótczesności, Hrsg. J. Stala, Tarnów 2010, S. 75-87.

Kościót i religijność Polaków 1945-1999, Hrsg. W. Zdaniewicz, T. Zembrzuski, Warszawa 2000.

Lombaerts H., Edukacja z perspektywy europejskiej, „Horyzonty Wychowania” (2002) $\mathrm{Nr}$ 2, S. 165-179.

Lombaerts H., ICT jako główne wsparcie globalnego świata i globalnego środowiska edukacyjnego, in: Hrsg. A. Bałoniak, J. Szpet, Między tradycja a wspótczesnościa, Poznań 2008, S. 73-90.

Lombaerts H., Komunikacja wiary dzisiaj, in: Komunikacja wiary w Trzecim Tysiącleciu, Hrsg. S. Dziekoński, Olecko 2000, S. 25-39. 
Lombaerts H., Osewska E., Historical and Geo-Political Reality of a United Europe, in: S. Gatt, H. Lombaerts, E. Osewska, A. Scerri, Catholic Education, European and Maltese Perspectives. Church School's response to future challenges, Floriana 2004, S. 27-43.

Lombaerts H., Osewska E., The Modern Christian Family as a First Setting for Religious and Moral Education?, in: Religious Education/Catechesis in the Family: A European Perspective, Hrsg. E. Osewska, J. Stala, Warszawa 2010, S. 11-25.

Lombaerts H., The Impact of the Status of Religion in Contemporary Society upon Interreligious Learning, in: Interreligious Learning, Hrsg. D. Pollefeyet, Leuven 2007, S. 81-86.

Mariański J., Johannes Paul II. als moralische Autorität in der polnischen Gesellschaft, "The Person and the Challenges" 2 (2012) Nr 1, S. 21-50.

Mariański J., Kościół katolicki w społeczeństwie obywatelskim, Lublin 1998.

Mariański J., Kryzys moralny czy transformacja wartości? Studium socjologiczne, Lublin 2001.

Mastalski J., Szkolne interakcje zaburzające skuteczne wychowanie, Kraków 2005.

Mierzwiński B., Kościót wobec problemu bezrobocia, Ząbki 2004.

Mierzwiński B., Mężczyzna - mą̇̇ - ojciec, Otwock 1996.

Oblicze współczesnej rodziny polskiej, Hrsg. B. Mierzwiński, E. Dybowska, Kraków 2003.

Orzeszyna J., Teologiczno-moralny aspekt niepłodności w małżeństwie, Kraków 2005.

Osewska E., L'educazione oggi in un'Europa diversificata, in: Europa, scuola, religioni. Monoteismi e confessioni cristiane per una nuova cittadinanza europea, Hrsg. F. Pajer, Torino 2005, S. 47-64.

Osewska E., Le pèlegrinage à Czestochowa. Lieu d'éducation dans la foi, « Lumen Vitae Revue » (2007), S. 247-265.

Osewska E., Możliwości i ograniczenia polityki rodzinnej w krajach Unii Europejskiej, in: Rodzina jako środowisko rozwoju człowieka, Hrsg. W. Piotrowski, Tarnów 2004, S. 89-119.

Osewska E., Stala J., W kierunku katechezy rodzinnej, Kielce 2003.

Osewska E., To Educate in a Diversified Europe, "The Person and the Challenges" 1 (2011) Nr 1, S. 71-88.

Osewska E., Uwarunkowania wychowania religijnego $w$ rodzinie, in: $W$ kregu rodziny, Hrsg. E. Osewska, J. Stala, Poznań 2003, S. 13-21.

Postawy społeczno-religijne diecezjan tarnowskich, Hrsg. W. Zdaniewicz, T. Zembrzuski, Warszawa 2001.

Prijatelj E., Geistige Dynamik von Vorschulkindern und deren Einführung in den Glauben, „Christlich pädagogische Blätter” (2007) Nr. 2, S. 100-104.

Prijatelj E., Psihološka dinamika rasti v veri, Ljubljana 2008

Przygoda W., Postuga charytatywna Kościoła w Polsce. Studium teologiczno-pastoralne, Lublin 2004.

Rodzina. Bezcenny dar i zadanie, Hrsg. J. Stala, E. Osewska, Radom 2006.

Rynio A., Integralne w myśli Jana Pawta II, Lublin 2004.

Skreczko A., Rola Kościoła katolickiego w kształtowaniu kultury pedagogicznej rodziców w Polsce, Białystok 2011. 
Skreczko A., Troska Kościoła katolickiego $w$ Polsce o matzeństwo i rodzinę $w$ okresie Wielkiej Nowenny Tysiaclecia (1957-1966). Studium teologiczno-pastoralne, Białystok 2002.

Solak A., Wychowanie chrześcijańskie i praca ludzka. Studium wspótzależności, Warszawa 2004.

Stala J., Der Mensch als Person: Die bestimmende Grundlage für Johannes Paul II. in seinem Bild von der Familie, ,The Person and the Challenges” 2 (2012) Nr 2, S. 41-59.

Stala J., Die Transzendenz als bestimmendes Merkmal der Person in der Anthropologie und der Pädagogik Johannes Pauls II., „,The Person and the Challenges” 2 (2012) Nr 1, S. 61-75.

Stala J., Familienkatechese in Polen um die Jahrhundertwende. Probleme und Herausforderungen, Tarnów 2008.

Stala J., Katecheza rodzinna. Próba teologicznego zarysu zagadnienia, in: Rodzina. Bezcenny dar i zadanie, Hrsg. J. Stala, E. Osewska, Radom 2006, S. 182-230.

Stala J., Osewska E., Sociological Aspects of Family Religious Education in Poland, in: Religious Education / Catechesis in the Family. A European Perspective, Hrsg. E. Osewska, J. Stala, Warszawa 2010, S. 167-177.

Szymański W., Towarzystwo dobroczynności wobec kwestii społecznych, Płock 2005.

Współdziałanie Kościoła i państwa na rzecz matżeństwa i rodziny, Hrsg. J. Krukowski, T. Śliwowski, Łomża 2005.

Wychowanie chrześcijańskie. Między tradycją a wspótczesnością, Hrsg. A. Rynio, Lublin 2007.

Zając J., Troska Kościoła o chorych, Płock 2005. 